\title{
Chronic respiratory disease among the elderly in South Africa: any association with proximity to mine dumps?
}

\author{
Vusumuzi Nkosi ${ }^{*}$, Janine Wichmann and Kuku Voyi ${ }^{\dagger}$
}

\begin{abstract}
Background: There is increasing evidence that environmental factors such as air pollution from mine dumps, increase the risk of chronic respiratory symptoms and diseases. The aim of this study was to investigate the association between proximity to mine dumps and prevalence of chronic respiratory disease in people aged 55 years and older.
\end{abstract}

Methods: Elderly persons in communities $1-2 \mathrm{~km}$ (exposed) and $5 \mathrm{~km}$ (unexposed), from five pre-selected mine dumps in Gauteng and North West Province, in South Africa were included in a cross-sectional study. Structured interviews were conducted with 2397 elderly people, using a previously validated ATS-DLD-78 questionnaire from the British Medical Research Council.

Results: Exposed elderly persons had a significantly higher prevalence of chronic respiratory symptoms and diseases than those who were unexposed., Results from the multiple logistic regression analysis indicated that living close to mine dumps was significantly associated with asthma ( $\mathrm{OR}=1.57 ; 95 \% \mathrm{Cl}: 1.20-2.05)$, chronic bronchitis $(\mathrm{OR}=1.74 ; 95 \mathrm{Cl}: 1.25$ - 2.39), chronic cough $(\mathrm{OR}=2.02 ; 95 \% \mathrm{Cl}: 1.58-2.57)$, emphysema $(\mathrm{OR}=1.75$; $95 \% \mathrm{Cl}: 1.11$ - 2.77), pneumonia (OR=1.38; 95\% Cl: 1.07 - 1.77) and wheeze (OR=2.01; 95\% Cl: 1.73 - 2.54). Residing in exposed communities, current smoking, ex-smoking, use of paraffin as main residential cooking/heating fuel and low level of education emerged as independent significant risk factors for chronic respiratory symptoms and diseases.

Conclusion: This study suggests that there is a high level of chronic respiratory symptoms and diseases among elderly people in communities located near to mine dumps in South Africa.

Keywords: Mine dumps, Chronic respiratory diseases, Elderly, South Africa

\section{Background}

Chronic respiratory diseases are among the leading causes of death worldwide [1]. A recent review indicated that developing countries are experiencing an increase in the prevalence of respiratory diseases [2] and projected trends of severity and frequency are likely to pose a public health challenge [3]. Studies have shown that both indoor and outdoor air pollution are the main risk factors for the burden of respiratory diseases $[4,5]$ and elderly people are mostly affected [6] as a result of normal and pathological

\footnotetext{
* Correspondence: vnkosi334@gmail.com

${ }^{+}$Equal contributors

School of Health Systems and Public Health, Faculty of Health Sciences, University of Pretoria, P.O. Box 2034, Pretoria 0001, South Africa
}

ageing [7]. A higher burden of respiratory diseases among the elderly could be of concern to South Africa's rapidly increasing population aged 60 years and above, currently the second largest in sub-Saharan Africa [8].

In developing countries where health risks of air pollution may be underappreciated and effective air pollution abatement techniques are lacking, people are continually exposed to concentrations that can have negative health effects in both the short and long term. Various risk factors have been associated with chronic respiratory diseases, including gender [9], socio-economic status [10], tobacco smoking habits [11], occupational environment [12] and polluting fuel used for residential cooking/ heating [13]. Studies conducted in South Africa on the 
prevalence of respiratory diseases have been in industrialized urban areas [14,15].

Mine dump facilities are the main source of airborne particulate matter pollution, the dust is blown into the surrounding communities and can potentially have adverse health effects on human health and ecology $[16,17]$. Communities located close to mine dumps are of lower socio-economic status, often children and the elderly. These communities consist of historically disenfranchised ethnic groups living in government-funded houses, informal settlements and retired homes [18]. Epidemiological studies have shown that residing near mines is a major risk for exposure to particulate matter and metals such as cadmium, lead, silica, manganese, lead and arsenic [19-21]. Exposure to mine dump dust that is that is rich in silica has been linked to the development of chronic bronchitis, emphysema and airflow obstruction [22]. Settle-able dust has a negative effect on visibility, when it forms dust plumes while its deposition on fabrics, buildings, vehicles and water tanks constitutes a nuisance [23]. The ongoing reclamation of mine dumps for gold recovery observed during the survey, is worsening dust pollution with further deterioration of ambient air quality in the study populations. Many epidemiological studies have linked the effects of ambient air pollution with respiratory diseases $[24,25]$. Elderly people are potentially highly vulnerable to the effect of ambient air pollution, due to normal and pathological aging [26].

No studies have investigated whether exposure to mine dust or living in close proximity to mine dumps poses an increased risk for respiratory diseases among elderly people or possible effect modifications between various air pollution sources, including mine dust.

This study is part of the bigger project initiated by Mine Health Safety Council of South Africa (MHSC) around communities located near mine dumps in Gauteng and North West provinces. It is, to the best of our knowledge, the first study that has investigated the association between potential risk factors and chronic respiratory diseases among elderly people staying in communities situated near mine dumps in South Africa. The aim of the study was to investigate whether the prevalence of chronic respiratory symptoms and diseases among the elderly community were associated with proximity to mine dumps. Effect modification between proximity to mine dumps and other air pollution sources was also investigated, for instance the type of fuel use for residential cooking/heating, tobacco smoking and history of occupational exposure to dust or chemical fumes.

\section{Methods}

\section{Study area and demographics}

Communities living 1-2 km (exposed) and $5 \mathrm{~km}$ (unexposed) from five pre-selected mine dumps in Gauteng and North West Provinces of South Africa were studied during November and December in 2012. Table 1 lists the selected communities and Figure 1 shows a map of the study area. The socio-economic and demographic profile of exposed and unexposed communities was similar.

\section{Study design and sample selection}

A cross-sectional epidemiological study design was applied. Face-to-face interviews were conducted using a previously validated ATS-DLD-78 questionnaire from the British Medical Research Council (BMRC) [27]. The study focused on elderly people (55 years old and above) who had been residing for a period of five years or more, in the study communities. A knock on the door approach was used to recruit study participants. The interviews were mainly in English and were translated into the local language if the respondent did not understand the questions.

Streets were randomly selected in each community. Four to five houses were then randomly selected in each street in a radial fashion. The sample size of each community was calculated using Epi Info version 7, with a total sample size of 3069. The population sizes were based on the 2001 census from Statistics South Africa because the results for census 2011 were not released when the study commenced. Twenty-two locally trained fieldworkers were employed, two per community listed in Table 1. Each fieldworker received thorough training

Table 1 Eleven communities selected in the study located in Gauteng and North West provinces, South Africa during November-December 2012

\begin{tabular}{llll}
\hline Mine dump facility & Province & Exposed communities $^{\mathbf{a}}$ & Unexposed communities $^{\mathbf{b}}$ \\
\hline Durban Roodepoort Deep (DRD) & Gauteng & Braamfischerville & Dobsonville \\
Crown Gold Recoveries (CGR) & Gauteng & Diepkloof, Riverlea, and Noordgesig & Orlando East \\
East Rand Proprietary Mines (ERPM) & Gauteng & Reiger Park & Windmill Park \\
Ergo & Gauteng & Geluksdal & Windmill Park \\
Anglo Gold Ashanti (AGA) & North West & Stilfontein & Jouberton \\
\hline
\end{tabular}

${ }^{\mathrm{a}} 1-2 \mathrm{~km}$ from mine dumps.

$\mathrm{b}_{5} \mathrm{~km}$ or more from mine dumps. 


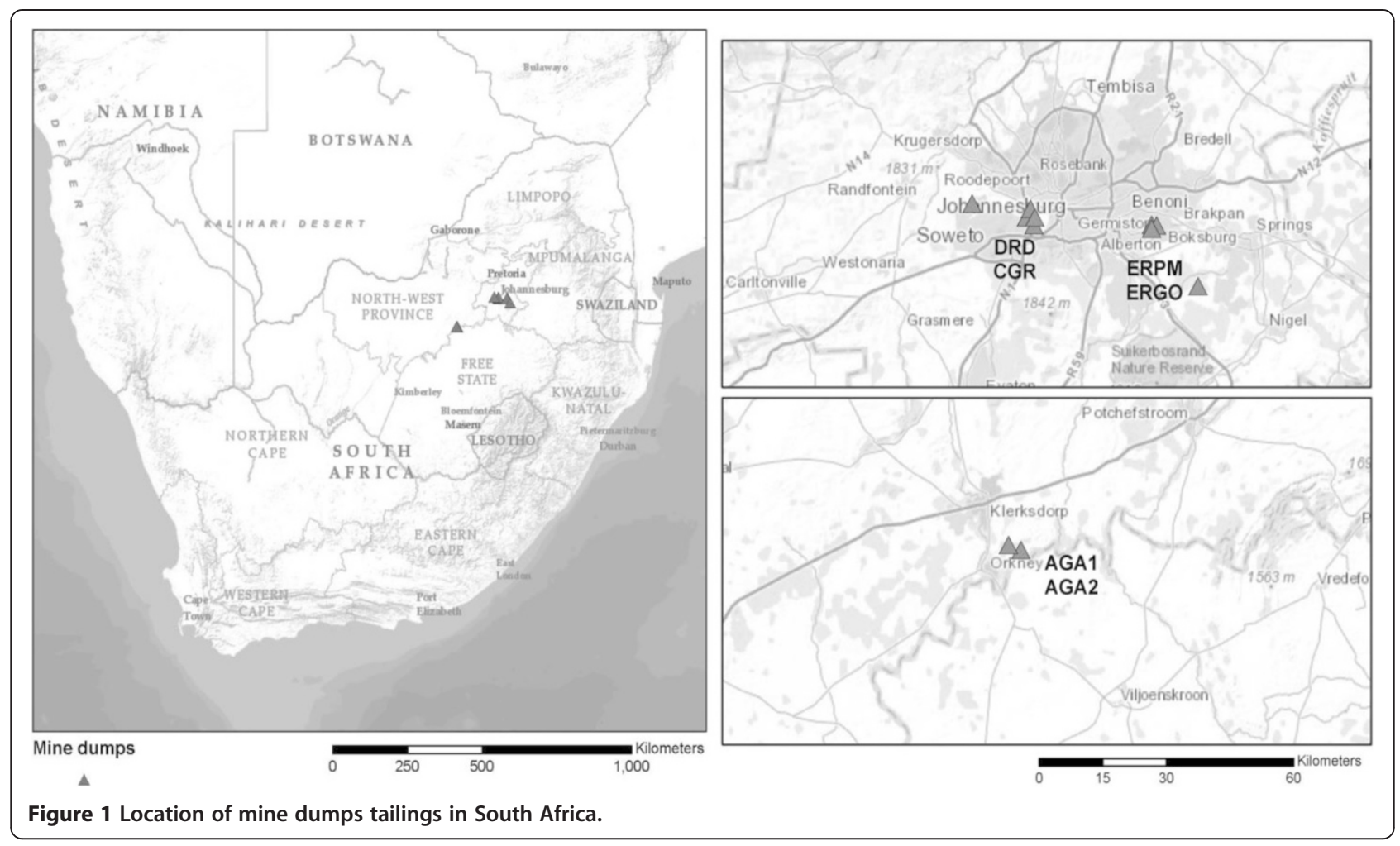

in conducting the interviews using the respiratory-health questionnaire, before the start of the survey.

\section{Exclusion criteria}

If a selected household had no elderly people or no one at home during the visit, or were unwilling to participate, the fieldworker proceeded to the next household.

\section{Quality control}

To maintain the quality of the interviews, fieldworkers randomly selected $10 \%$ of homes and re-administered the same questionnaire to the same previously interviewed participants to verify their responses. This was performed 15 to 20 days after the first interview. Ten percent deviations within the interviews were deemed unacceptable.

\section{Health outcomes}

Having asthma, chronic bronchitis, chronic cough, emphysema, pneumonia and wheeze were classified on the basis of positive answers to the following questions:

Asthma: "Was the asthma confirmed by the doctor?"

Chronic bronchitis: "Was the chronic bronchitis confirmed by the doctor?"

Chronic cough: "Do you cough most days for 3 consecutive months or more during the year?"

Emphysema: "Was the emphysema confirmed by the doctor?"
Pneumonia: "Was the pneumonia confirmed by the doctor?"

Wheeze: "Does your chest ever sound whistling most days or nights?"

\section{Main exposure factor}

The main exposure factor of interest in this study was based on the distance between the study population and a mine dump (Table 1).

\section{Confounders}

Potential confounding variables included other air pollution sources: active smoking by participants (yes/no), main type of residential cooking/heating fuel (electricity, gas, paraffin, wood/coal). Additional confounders considered were: age (years), level of education (no schooling, primary, secondary, tertiary), sex (female/male), occupational exposure history to dust/chemical fumes (yes/no).

\section{Statistical analyses}

Two technicians entered the collected questionnaire data into a database set up in Epi Info version 3.5.3. Data were analyzed using Stata version 12. Prevalence of the health outcome; the proportion of air pollution sources under investigation; and confounding variables, were calculated by dividing the number of participants who responded affirmatively by the number of questionnaires completed. Therefore each question had a different sample size. 
Observations marked as "do not know", "not stated", or "other responses" were set as missing, but were included in the descriptive analyses. Only two explanatory variables such as age and main residential heating and cooking fuel type had missing observations. Responses to the number cigarettes smoked per day were very low and not included in the analysis. A chi square test was applied, to determine the relationship between community (exposed/unexposed) and confounding variables. Crude and adjusted odds ratios (ORs) and 95\% confidence intervals (CI) were calculated using univariate and multiple logistic regression analysis (LRA) to estimate the likelihood of having asthma, chronic bronchitis, chronic cough, emphysema, pneumonia and wheeze. Missing values were automatically excluded in each LRA model; therefore each multiple LRA model had a different sample size. To obtain adjusted ORs for the effect of "community (exposed/unexposed)" on the outcomes were placed in an initial LRA model. This was followed by the addition of a potential confounder in a stepwise manner starting with the most statistical significant from the univariate analysis. Each time a new potential confounder was added to the model if the effect estimate between the exposure of interest and respiratory outcome already in the models changed by more than $5 \%$, the additional variable was retained in the final multiple LRA otherwise the variable was removed and a different one was added [28]. The most parsimonious multiple LRA models were reported, i.e. those with variables having a p-value $<0.05$ [29]. Community (exposed/unexposed) was considered as the main exposure factor and therefore was included in all models for each outcome of interest regardless of whether it was statistically significant in the univariate analyses.

Effect modification between community (exposed/unexposed) and other air pollution source variables, such as smoking habits, occupational exposure history to dust/ chemical fumes, and residential cooking/heating fuel type, was investigated by including a multiplicative term in the model.

\section{Ethics approval}

Ethical approval (number: 235/2011) was obtained from the Research Ethics Committee, Faculty of Health Sciences, University of Pretoria. A verbal and written consent was obtained before commencement of the interviews.

\section{Results}

Only completed questionnaires (2397) were used for data analysis. This included 1499 (63\%) study participants from exposed and 898 (37\%) from unexposed communities (Table 2). The number of females in the study was slightly higher than males. Most of the study participants were in the age group 55 to 59 years. Overall, the majority of participants from both study communities had obtained
Table 2 Demographic characteristics and air pollution variables by type of community in Gauteng and North West provinces, South Africa during November-December 2012

\begin{tabular}{|c|c|c|c|}
\hline & \multicolumn{2}{|l|}{ Community } & \multirow[t]{2}{*}{ p-value ${ }^{c}$} \\
\hline & $\begin{array}{l}\text { Exposed }^{a} \\
(n=1499)\end{array}$ & $\begin{array}{l}\text { Unexposed }^{b} \\
(n=898)\end{array}$ & \\
\hline \multicolumn{4}{|l|}{ Sex } \\
\hline Female & 774 (51.6) & $472(52.3)$ & 0.66 \\
\hline Male & $725(48.4)$ & $426(47.4)$ & \\
\hline \multicolumn{4}{|l|}{ Age (in years) } \\
\hline $55-59$ & $500(33.4)$ & $225(25.1)$ & $<0.001$ \\
\hline $60-64$ & $405(27.0)$ & 221 (24.6) & \\
\hline $65-69$ & $228(15.2)$ & $125(13.9)$ & \\
\hline $70-84$ & 309 (20.6) & $278(31.0)$ & \\
\hline$\geq 85$ & $48(3.2)$ & $29(3.2)$ & \\
\hline Missing & $9(0.6)$ & $20(2.2)$ & \\
\hline Population group & & & $<0.001$ \\
\hline Black & 1006 (41.9) & $695(29.0)$ & \\
\hline Coloured & 493 (20.6) & $203(8.5)$ & \\
\hline \multicolumn{4}{|l|}{ Level of education } \\
\hline No schooling & $262(17.5)$ & $271(30.2)$ & $<0.001$ \\
\hline Primary & $479(32.0)$ & $287(32.0)$ & \\
\hline Secondary & $691(46.1)$ & $332(37.0)$ & \\
\hline Tertiary & $67(4.5)$ & $8(0.8)$ & \\
\hline \multicolumn{4}{|l|}{ Smoking habits } \\
\hline Non-smoker & $888(59.2)$ & $598(66.6)$ & $<0.001$ \\
\hline Ex-smoker & 234 (15.6) & 187 (20.8) & \\
\hline Current smoker & $377(25.2)$ & $113(12.6)$ & \\
\hline \multicolumn{4}{|c|}{$\begin{array}{l}\text { Occupational exposure } \\
\text { history to dust/chemical fumes }\end{array}$} \\
\hline Yes & $637(42.5)$ & 149 (16.6) & $<0.001$ \\
\hline No & $862(57.5)$ & $749(83.4)$ & \\
\hline \multicolumn{4}{|c|}{$\begin{array}{l}\text { Main residential heating/ } \\
\text { cooking fuel type }\end{array}$} \\
\hline Electricity & $1422(94.9)$ & $783(87.2)$ & $<0.001$ \\
\hline Gas & $31(2.1)$ & $67(7.5)$ & \\
\hline Paraffin & $25(1.7)$ & $6(0.7)$ & \\
\hline Open fires & $1(0.07)$ & $13(1.5)$ & \\
\hline Missing & $20(1.3)$ & $29(3.2)$ & \\
\hline
\end{tabular}

Figures in parentheses are percentages.

aExposed: communities located 1-2 km from mine dumps.

bUnexposed: communities located $5 \mathrm{~km}$ or more from mine dumps.

$c_{p}$-values of the Chi-square test.

secondary level education. The proportion of current smokers and those with a history of occupational exposure history to dust/chemical fumes, in exposed communities, was double that of the unexposed. A majority of participants from both exposed and unexposed communities 
reported electricity as the main source of residential fuel for heating/cooking.

The prevalence of asthma (17.3\%), chronic bronchitis (13.4\%), chronic cough (26.6\%), emphysema (5.6\%), pneumonia (17.1\%) and wheeze (24.7\%), in the exposed communities was higher than that of the unexposed communities, where the proportions were $12.1 \%, 7.5 \%$, $18 \%, 3.3 \%, 13.9 \%$ and $19.3 \%$, respectively (Figure 2 ).

The prevalence of asthma, chronic bronchitis, chronic cough, emphysema, pneumonia, and wheeze per each risk factor considered in this study are shown in Additional file 1: Table S1. Crude and adjusted ORs for all risk factors except the main exposure factor are shown in Additional file 2: Tables S2 and Additional file 3: Table S3.

Results from the multiple LRA (Table 3) indicated that living in the exposed communities was significantly associated with asthma $(\mathrm{OR}=1.57 ; 95 \% \mathrm{CI}: 1.20-2.05)$, chronic bronchitis ( $\mathrm{OR}=1.74 ; 95 \% \mathrm{CI}: 1.25$ - 2.39), chronic cough $(\mathrm{OR}=2.02 ; 95 \% \mathrm{CI}: 1.58-2.57)$, emphysema $(\mathrm{OR}=1.75$; 95\% CI: $1.11-2.77)$, pneumonia $(\mathrm{OR}=1.38 ; 95 \% \mathrm{CI}$ : $1.07-1.77)$ and wheeze (OR $=2.01$; 95\% CI: $1.73-2.54)$. Sex was not associated with any of the health outcomes considered in this study. The study participants who were in the age group between 70-84 years were at an increased likelihood of having chronic bronchitis (67\%), emphysema (81\%) and pneumonia (36\%). Coloured participants were less like to experience cough $(\mathrm{OR}=0.55$; 95\% CI: $0.42-$ 0.71 ) and wheeze (OR $=0.54$; $95 \% \mathrm{CI}$ : $0.44-0.66)$ as compared to black. Participants with primary level as their highest education were $50 \%$ more likely to have asthma. Having secondary education was associated with chronic bronchitis (OR $=1.45 ; 95 \%$ CI: $1.01-2.22)$ and wheeze $(\mathrm{OR}=1.54 ; 95 \% \mathrm{CI}: 1.54-1.98)$. Current and ex-smoking significantly increased the likelihood of having chronic cough, wheeze, asthma, emphysema, pneumonia, and were not associated with chronic bronchitis respectively. Occupational exposure history to dust/chemical fumes was significantly associated with chronic bronchitis $(\mathrm{OR}=$ 1.43; $95 \%$ CI: 1.07 - 1.91). Using polluting fuels, such as paraffin or gas for residential cooking/heating had significant detrimental association with chronic cough $(\mathrm{OR}=$ 2.03; 95\% CI: $1.13-4.78)$ and pneumonia $(\mathrm{OR}=2.40$; $95 \%$ CI: 1.11 - 5.17) (Additional file 3: Table S3).

No significant effect modification between community type (exposed/unexposed) and other air pollution source variables was observed (results not shown).

\section{Discussion}

This is the first study that investigated the prevalence and risk factors associated with chronic respiratory symptoms and diseases and among elderly people in communities exposed to mine dumps in South Africa. The results of this study suggest that there is a high prevalence of asthma, chronic bronchitis, chronic cough, emphysema, pneumonia and wheeze in the seven exposed communities. Residing in exposed communities, smoking habits, use of paraffin for residential cooking/heating, and having a low level of education emerged as significant risk factors for chronic respiratory symptoms and diseases.

The risk of exposure to particulate matter from mine dumps is well documented by international research studies [30-32]. An exposure assessment study done in one of the mine dumps in this study showed that the ambient concentration of particulate matter with an aerodynamic diameter less than $10 \mu \mathrm{m}\left(\mathrm{PM}_{10}\right)$ exceeded by far the 24-hour limit set by the South African Department of Environmental Affairs $\left(180 \mu \mathrm{g} \cdot \mathrm{m}^{-3}\right)$ [16,33]. Residential developments in some communities are a stone throw from the mine dump, resulting in elevated exposure to particulate matter [34]. Therefore, respiratory diseases and symptoms could be aggravated or originated as a result of exposure to dust emanating from mine dumps.

No significant differences were observed between the prevalence of chronic respiratory symptoms and diseases in males and females, and sex was not associated with any of the health outcomes considered in this study. Previous studies have reported that males were at increased risk for respiratory diseases $[35,36]$. This difference may
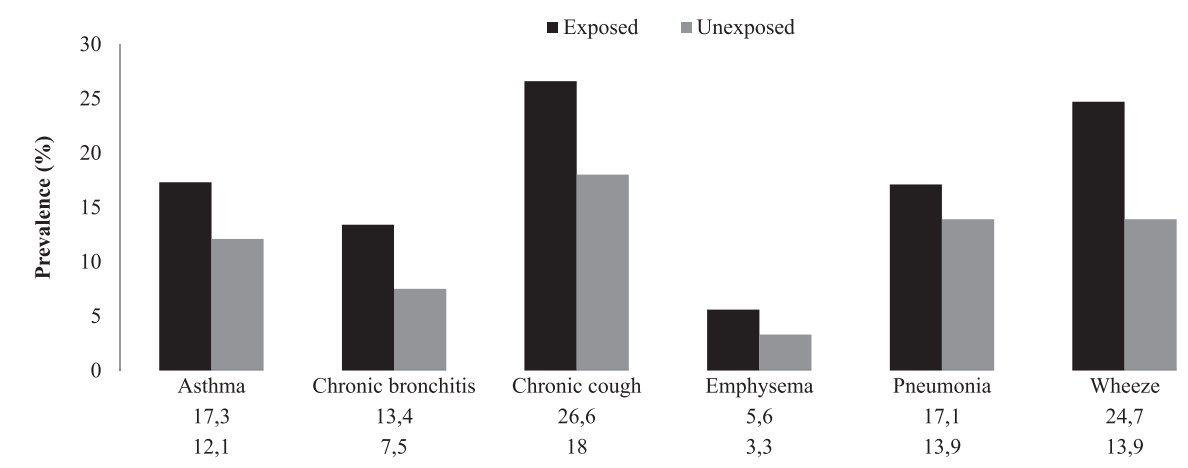

Figure 2 Prevalence of chronic respiratory symptoms and diseases stratified by type of community located 1-2 km and $\geq 5 \mathrm{~km}$ from mine dumps in Gauteng and North West provinces, South Africa during November-December 2012. 
Table 3 Univariate and multivariate analyses of chronic respiratory symptoms/diseases and diseases in all 11-study communities located 1-2 km and $\geq 5 \mathrm{~km}^{*}$ from mine dumps in Gauteng and North West provinces, South Africa during November-December 2012

\begin{tabular}{lllllll}
\hline Chronic respiratory symptoms/diseases & Crude OR & $\mathbf{( 9 5 \% ~ C I )}$ & $\boldsymbol{p}$-value & Adjusted OR & (95\% Cl) & $\boldsymbol{p}$-value \\
\hline Asthma $^{\text {a }}$ & 1.49 & $(1.17-1.90)$ & 0.001 & 1.57 & $(1.20-2.05)$ & 0.001 \\
Chronic bronchitis $^{b}$ & 1.92 & $(1.44-2.57)$ & $<0.001$ & 1.74 & $(1.26-2.39)$ & 0.001 \\
Chronic cough $^{c}$ & 1.77 & $(1.43-2.20)$ & $<0.001$ & 2.02 & $(1.58-2.57)$ & $<0.001$ \\
Emphysema $^{\mathrm{d}}$ & 1.72 & $(1.12-2.63)$ & 0.013 & 1.75 & $(1.11-2.77)$ & 0.016 \\
Pneumonia $^{\mathrm{e}}$ & 1.25 & $(1.01-1.58)$ & 0.018 & 1.38 & $(1.07-1.77)$ & 0.014 \\
Wheeze $^{f}$ & 1.96 & $(1.65-2.32)$ & $<0.001$ & 2.01 & $(1.73-2.54)$ & $<0.001$ \\
\hline
\end{tabular}

*Communities located $\geq 5 \mathrm{~km}$ (unexposed) from mine dumps used as reference category.

a-f: Models adjusted for sex, age, population group, smoking habits, occupational exposure history to dust/chemical fumes and main residential heating/cooking fuel type.

result from differential occupational exposure rates and smoking between males and females.

Aging is normally associated with an increased risk of respiratory symptoms and diseases [36,37], this might be attributed to anatomical, physiological and immunological changes that occur in the respiratory system during aging [38]. In this study increase in age was not significantly associated with having chronic respiratory symptoms and diseases, survivor effect could be a possible explanation for these observations. A research study conducted in South Africa showed being coloured was associated with the presence chronic lung diseases among the elderly people [39]. However, in this study a significant protective effect was observed. Primary and secondary education levels were significant risk factors for respiratory symptoms and diseases. Lower education levels are known to be linked to low socio-economic status and have been identified as a risk factor for respiratory symptoms and diseases [40]. A national household survey conducted in South Africa reported higher education level as a protective factor for respiratory diseases [41]. The findings of this study support this association.

Association of smoking habits with respiratory diseases and symptoms is not novel [42-44]. Current and exsmoking was significantly associated with chronic cough, wheeze, asthma, emphysema and pneumonia. Ex-smokers were at a higher risk than current smokers of having the latter. Being diagnosed as having chronic respiratory symptoms and disease might be the reason why respondents stopped smoking. Another possibility might have been advice from doctors, as it has been shown that physician's advice could contribute to smoking cessation [45].

The respiratory system is susceptible to harm from occupational exposures due to direct contact with the ambient environment, and inhalation of possible toxic substances [46]. Occupational exposure history to dust/ chemicals was not associated with respiratory diseases or symptoms. The findings of this study are in contrast to those of other research studies in this respect [47-49].
Domestic use of paraffin or gas appliances has been associated with respiratory symptoms and diseases in children, less consistently with adults and elderly people $[50,51]$. In this study domestic use of paraffin and gas was associated with an increased risk of respiratory symptoms and diseases, possibly caused by oxides of nitrogen or carbon monoxide generated when gas or paraffin is burned [51].

This study has some limitations inherent to crosssectional epidemiological designs. Firstly, the study cannot provide any evidence of causality. Secondly, no quantitative air pollution exposure assessment was conducted. Thirdly, we relied on doctor diagnosed respiratory diseases, which, although specific, can cause an underestimation of disease prevalence. Therefore it is assumed that several individuals with respiratory diseases were missed due to restrictive definitions employed in this study, as a result of poor access to health care facilities associated with black poor communities [52]. The possibility of estimating falsely low prevalence figures cannot be ignored. However, the observed high prevalence of respiratory diseases in exposed communities cannot only be attributed to a strict definition used, but to a complex interaction of social, economic, and behavioral factors such as air pollution, under-nutrition, poor access to healthcare, or life-style behaviors [53,54]. Fourthly, the interviewer error might have occurred in the translation of the questions to the local language during the interview of some study participants who did not understand English. Fifthly, unwillingness of the respondents to provide honest answers or giving socially desirable responses should be taken into account in the interpretation of the results. Sixthly, no lung function tests and/or spirometry, were conducted during the study. Lastly, the differential participation rate between exposed and unexposed communities is of concern and may well have introduced response bias, which is likely to overestimate the prevalence estimates derived from our crosssectional study and also bias the association in either direction. 
An advantage of this study is that $10 \%$ of the study participants were interviewed twice, with $96 \%$ repeatability observed.

\section{Conclusion}

The study findings suggest that there is a high prevalence chronic respiratory symptoms and diseases among the elderly in communities located near mine dumps. The significant risk factors are proximity to mine dump, smoking habits, low level of education and domestic use of gas or paraffin.

\section{Additional files}

Additional file 1: Table S1. Prevalence of chronic respiratory symptoms and diseases in relation to independent variables in all 11 -study communities located $1-2 \mathrm{~km}$ and $\geq 5 \mathrm{~km}$ from mine dumps in Gauteng and North West provinces, South Africa during November-December 2012.

Additional file 2: Table S2. Crude odds ratios with 95\% confidence intervals of chronic respiratory symptoms and diseases in all 11-study communities located $1-2 \mathrm{~km}$ and $\geq 5 \mathrm{~km}$ from mine dumps in Gauteng and North West provinces, South Africa during November-December 2012.

Additional file 3: Table S3. Adjusted odds ratios with $95 \%$ confidence intervals of chronic respiratory symptoms and diseases in all 11-study communities located $1-2 \mathrm{~km}$ and $\geq 5 \mathrm{~km}$ from mine dumps in Gauteng and North West provinces, South Africa during November-December 2012.

\section{Abbreviations}

Cl: Confidence intervals; MLRA: Multilevel logistic regression analysis; AGA: Anglo gold ashanti; CGR: Crown gold recoveries; DRD: Durban roodepoort deep; ERPM: East rand proprietary mines; SSA: Statistics South Africa; NRF - DAAD: National research fund - deutscher akademischer austausch dienst.

\section{Competing interest}

The authors declare that they have no competing interests.

\section{Authors' contributions}

VN and KV participated in the design of the study, data collection, statistical analysis and interpretation of the results, drafted and critically revised the manuscript. JW participated in the statistical analysis and interpretation of the results, drafted and critically revised the manuscript. All authors have read and approved the final manuscript.

\section{Acknowledgements}

We thank everybody who participated in the questionnaire interviews, Mr. Moses Kebalepile and all the fieldworkers who assisted in data collection, the data technicians for the data capturing, Statistics South Africa (SSA) for providing the population sizes of elderly people in each study community, and lastly Professor Cheryl McCrindle for language editing.

\section{Funding}

This study was funded by the Mine Health Safety Council (MHSC) and National Research Fund - Deutscher Akademischer Austausch Dienst (NRF - DAAD) and the University of Pretoria (UP).

Received: 19 July 2014 Accepted: 19 March 2015

Published online: 03 April 2015

\section{References}

1. Lozano R, Naghavi M, Foreman K, Lim S, Aboyans V, Abraham J, et al. Global and regional mortality from 235 causes of death for 20 age groups in 1990 and 2010: a systematic analysis for the Global Burden of Disease Study 2010. Lancet. 2012;380(9859):2095-128.

2. Boutayeb A, Boutayeb $S$. The burden of non communicable diseases in developing countries. Int J Equity Health. 2005;4(2):1-8.

3. Ait-Khaled N, Enarson D, Bousquet J. Chronic respiratory diseases in developing countries: the burden and strategies for prevention and management. Bull World Health Organ. 2001;79(10):971-9.

4. Al Saadi MM. Air pollution and respiratory health: An evolving epidemic. Pakistan J Med Sci. 2010;26(1):239-43.

5. Arbex MA, Santos Ude P, Martins LC, Saldiva PHN, Pereira LAA, Braga ALF. Air pollution and the respiratory system. J Bras Pneumol. 2012;38(5):643-55.

6. Bell ML, Zanobetti A, Dominici F. Evidence on vulnerability and susceptibility to health risks associated with short-term exposure to particulate matter: a systematic review and meta-analysis. Am J Epidemiol. 2013;178(6):865-76.

7. Ko FWS, Lai CKW, Woo J, Ho SC, Ho CWM, Goggins W, et al. 12-year change in prevalence of respiratory symptoms in elderly Chinese living in Hong Kong. Respir Med. 2006;100(9):1598-607.

8. Joubert J, Bradshawb D (Eds): Chronic disease lifestyle in South Africa: 1995-2005. South African Medical Research Council 2006;1:204-219, Techical report

9. Han MK, Postma D, Mannino DM, Giardino ND, Buist S, Curtis JL, et al. Gender and chronic obstructive pulmonary disease: why it matters. Am J Respir Crit Care Med. 2007;176(12):1179-84.

10. World Health Oragnisation. Review of Evidence on Health Aspects of Air Pollution - REVIHAAP Project. 2013. Techinical report.

11. Forey BA, Thornton AJ, Lee PN. Systematic review with meta-analysis of the epidemiological evidence relating smoking to COPD, chronic bronchitis and emphysema. BMC Pulm Med. 2011;11(36):1-61.

12. Omland $\mathrm{O}$, Würtz ET, Aasen TB, Blanc P, Brisman JB, Miller MR, et al. Occupational chronic obstructive pulmonary disease: a systematic literature review. Scand J Work Environ Health. 2014;40(1):19-35.

13. Torres-Duque C, Maldonado D, Pérez-Padilla R, Ezzati M, Viegi G. Biomass fuels and respiratory diseases: a review of the evidence. Proc Am Thorac Soc. 2008:5(5):577-90.

14. Nriagu J, Robins T, Gary L, Liggans G, Davila R, Supuwood K, et al. Prevalence of asthma and respiratory symptoms in south-central Durban. South Africa Eur J Epidemiol. 1999;15(8):747-55.

15. Wichmann J, Wolvaardt JE, Maritz C, Voyi KW. Household conditions, eczema symptoms and rhinitis symptoms: relationship with wheeze and severe wheeze in adolescents living in the Polokwane area, South Africa. J Asthma. 2007;44(8):659-66.

16. Ojelede ME, Annegarn HJ, Kneen MA. Evaluation of aeolian emissions from gold mine tailings on the Witwatersrand. Aeolian Res. 2012;3(4):477-86.

17. Stovern M, Felix O, Csavina J, Rine KP, Russell MR, Jones RM, et al. Simulation of windblown dust transport from a mine tailings impoundment using a computational fluid dynamics model. Aeolian Res. 2014;14(1):1-10.

18. Wright CY, Matooane M, Oosthuizen MA, Phala N. Risk perceptions of dust and its impacts among communities living in a mining area of the Witwatersrand. South Africa Clean Air J. 2014;24(1):22-7.

19. Hu H, Shine J, Wright O. Waste : The Challenge Posed to Children's Health by Mixtures of Toxic Waste: The Tar Creek Superfund Site as a Case-Study. Pediatr Clin N Am. 2008:54(1):1-19.

20. Meza-Figueroa D, Maier RM, de la O-Villanueva M, Gómez-Alvarez A, Moreno-Zazueta A, Rivera J, et al. The impact of unconfined mine tailings in residential areas from a mining town in a semi-arid environment: Nacozari, Sonora, Mexico. Chemosphere. 2009;77(1):140-7.

21. Moreno ME, Acosta-Saavedra LC, Meza-Figueroa D, Vera E, Cebrian ME, Ostrosky-Wegman P, et al. Biomonitoring of metal in children living in a mine tailings zone in Southern Mexico: A pilot study. Int J Hyg Environ Health. 2010;213(4):252-8.

22. Wang $X$, Yano E, Nonaka $K$, Wang $M$, Wang Z. Respiratory impairments due to dust exposure: a comparative study among workers exposed to silica, asbestos, and coal mine dust. Am J Ind Med. 1997;31(5):495-502.

23. About dust-test and storms. [http://www.bom.gov.au/nsw/sevwx/facts/dust. shtml]

24. Brunekreef B, Holgate ST. Air pollution and health. Lancet. 2002;360(9341):1233-42.

25. Chen $\mathrm{H}$, Goldberg MS, Villeneuve PJ. A systematic review of the relation between long-term exposure to ambient air pollution and chronic diseases. Rev Environ Health. 2008;23(4):243-97. 
26. Bentayeb M, Simoni M, Baiz N, Norback D, Baldacci S, Maio S, et al Adverse respiratory effects of outdoor air pollution in the elderly. Int J Tuberc Lung Dis. 2012;16(9):1149-61.

27. Comstock GW, Tockman MS, Helsing KJ, Hennesy KM. Standardized respiratory questionnaires: comparison of the old with the new. Am Rev Respir Dis. 1979;119(1):45-53.

28. Groenwold $\mathrm{RHH}$, Klungel $\mathrm{OH}$. Selection of confounding variables should not be based on observed associations with exposure. Eur J Epidemiol. 2011;26(1):589-93.

29. Gortmaker SL, Hosmer DW, Lemeshow S. Applied Logistic Regression. Cotemp Sociol. 2nd ed. New York: John Wiley and Sons; 1994. p. 159.

30. Mayan ON, Gomes MJ, Henriques A, Silva S, Begonha A. Health survey among people living near an abandoned mine. A case study: Jales mine, Portugal. Environ Monit Assess. 2006;123(1-3):31-40.

31. Chang P, Kim JY, Kim KW. Concentrations of arsenic and heavy metals in vegetation at two abandoned mine tailings in South Korea. Environ Geochem Health. 2005;27(2):109-19.

32. Kon LC, Durucan S, Korre A. The development and application of a wind erosion model for the assessment of fugitive dust emissions from mine tailings dumps. Int J Min Reclamat Environ. 2007;21(3):198-218.

33. National Environmental Management. Air Quality Act 39 of 2004, Government Notice Gazette. 2005. Gazette No.28016.

34. Oguntoke O, Ojelede ME, Annegarn HJ. Frequency of Mine Dust Episodes and the Influence of Meteorological Parameters on the Witwatersrand Area, South Africa. Int J Atmos Sci. 2013;2013(1):1-10.

35. Ferré A, Fuhrman C, Zureik M, Chouaid C, Vergnenègre A, Huchon G, et al. Chronic bronchitis in the general population: influence of age, gender and socio-economic conditions. Respir Med. 2012;106(3):467-71.

36. Deveci F, Deveci SE, Türkoğlu S, Turgut T, Kirkil G, Rahman S, et al. The prevalence of chronic obstructive pulmonary disease in Elazig, Eastern Turkey. Eur J Intern Med. 2011;22(2):172-6.

37. Brashier B, Londhe J, Madas S, Vincent V, Salvi S. Prevalence of Self-Reported Respiratory Symptoms, Asthma and Chronic Bronchitis in Slum Area of a Rapidly Developing Indian City. Open J Respir Dis. 2012;2(3):73-81.

38. Sharma G, Goodwin J. Effect of aging on respiratory system physiology and immunology. Clin Interv Aging. 2006;1(3):253-60.

39. Phaswana-Mafuya N, Peltzer K, Chirinda W, Musekiwa A, Kose Z, Hoosain E, et al. Self-reported prevalence of chronic non-communicable diseases and associated factors among older adults in South Africa. Glob Health Action. 2013;6(20936):1-7.

40. Kanervisto M, Vasankari T, Laitinen T, Heliövaara M, Jousilahti P, Saarelainen S. Low socioeconomic status is associated with chronic obstructive airway diseases. Respir Med. 2011;105(8):1140-6.

41. Ehrlich RI, White N, Norman R, Laubscher R, Steyn K, Lombard C, et al. Predictors of chronic bronchitis in South African adults. Int J Tuberc Lung Dis. 2004;8(3):369-76.

42. Godtfredsen N, Prescott E. Benefits of smoking cessation with focus on cardiovascular and respiratory comorbidities. Clin Respir J. 2011;5(4):187-94.

43. Baena-Cagnani CE, Gómez RM, Baena-Cagnani R, Canonica GW. Impact of environmental tobacco smoke and active tobacco smoking on the development and outcomes of asthma and rhinitis. Curr Opin Allergy Clin Immunol. 2009;9(2):136-40.

44. Heloma A, Nurminen M, Reijula K, Rantanen J. Smoking prevalence, smoking-related lung diseases, and national tobacco control legislation. Chest. 2004;126(6):1825-31.

45. Research Committee of the British Thoracic Society. Smoking cessation in patients : two further studies by the British Thoracic Society. Thorax. 1990;45(11):835-40.

46. Balmes JR. Occupational respiratory diseases. Prim Care. 2000;27(4):1009-38.

47. Buist AS, McBurnie MA, Vollmer WM, Gillespie S, Burney P, Mannino DM, et al. International variation in the prevalence of COPD (the BOLD Study): a population-based prevalence study. Lancet. 2007;370(9589):741-50.

48. Blanc PD, Iribarren C, Trupin L, Earnest G, Katz PP, Balmes J, et al. Occupational exposures and the risk of COPD: dusty trades revisited. Thorax. 2009;64(1):6-12.

49. Lam KBH, Yin P, Jiang CQ, Sen ZW, Adab P, Miller MR, et al. Past dust and GAS/FUME exposure and COPD in Chinese: the Guangzhou Biobank Cohort Study. Respir Med. 2012;106(10):1421-8.

50. Franklin PJ, Loveday J, Cook A. Unflued gas heaters and respiratory symptoms in older people with asthma. Thorax. 2012;67(4):315-20.
51. Jarvis D, Chinn S, Luczynska C, Burney P. Association of respiratory symptoms and lung function in young adults with use of domestic gas appliances. Lancet. 1996;347(8999):426-31.

52. Harris B, Goudge J, Ataguba JE, Mclntyre D, Nxumalo N, Jikwana S, et al. Inequities in access to health care in South Africa. J Public Health Policy. 2011;32 Suppl 1:S102-23.

53. Aggarwal AN, Chaudhry K, Chhabra SK, D'Souza GA, Gupta D, Jindal SK, et al. Prevalence and risk factors for bronchial asthma in Indian adults: a multicentre study. Indian J Chest Dis Allied Sci. 2006;48(1):13-22.

54. Agarwal S, Srivastava A, Kumar S. Urban Health in Developing Countries. Perspect Knowl Manag Urban Health. 2010;1(1):61-94.

\section{Submit your next manuscript to BioMed Central and take full advantage of:}

- Convenient online submission

- Thorough peer review

- No space constraints or color figure charges

- Immediate publication on acceptance

- Inclusion in PubMed, CAS, Scopus and Google Scholar

- Research which is freely available for redistribution 